\section{Kidney \\ Blood Pressure Research}

Original Paper

\title{
Asymmetric Dimethylarginine and Progression of Chronic Kidney Disease - a One-Year Follow-Up Study
}

\author{
Jaromír Eiselta ${ }^{a}$ Daniel Rajdl ${ }^{b} \quad$ Jaroslav Racek ${ }^{b} \quad$ Michal Vostrýb $^{b} \quad$ Kamila Rulcováa \\ Jan Wirtha
}

aDepartment of Internal Medicine I; 'bInstitute of Clinical Biochemistry and Hematology, Charles University, Medical School and Teaching Hospital Plzeň, Czech Republic

\section{Key Words}

Asymmetric dimethylarginine - ADMA - Advanced glycation end products - AGE - Advanced oxidation protein products $\bullet$ AOPP $\bullet$ Oxidative stress $\bullet$ Chronic kidney disease $\bullet$ Chronic kidney disease progression

\begin{abstract}
Background/Aims: Asymmetric dimethylarginine (ADMA) is a prognostic factor in patients with chronic kidney disease (CKD). However, the relationships among factors influencing the metabolism of ADMA and the CKD progression are not fully understood. Methods: Serum ADMA, and variables related to the metabolism of ADMA were measured in 181 non-dialysis patients (CKD stages 3-5) and in 46 controls. Patients were assessed at baseline, and 6 and 12 months after the initiation of the study. Results: Patients had increased baseline ADMA, advanced glycation end products (AGE), and advanced oxidation protein products (AOPP) compared with controls $(P<0.001)$. In a total of 164 patients who completed a one-year study, the estimated GFR (eGFR) declined from $23.5(17.7-36) \mathrm{mL} / \mathrm{min} / 1.73 \mathrm{~m}^{2}$ to 21 (14.731.5) $(P=0.018)$, AGE rose from $1.58(1.38-1.90) \mu \mathrm{mol} / \mathrm{L}$ to $1.76(1.52-2.21)(P<0.001)$, while ADMA, AOPP, tubular function, and proteinuria remained stable. In a multiple regression model (adjusted $R^{2}=0.49, P<0.0001$ ), the interaction of relatively higher baseline eGFR, i.e. $>25 \mathrm{~mL} / \mathrm{min} / 1.73 \mathrm{~m}^{2}$, with higher ADMA $(P=0.02)$ and higher AOPP $(P=0.04)$ predicted the severest decrease in eGFR per year. Other predictors of progression were higher baseline AGE $(P<0.001)$, proteinuria $(P=0.003)$, hypertension $(P=0.01)$, and higher baseline eGFR $(P=0.03)$. Conclusion: Elevated ADMA and markers of oxidative stress were strong predictors of progression in patients with eGFR between $25-40 \mathrm{~mL} / \mathrm{min} / 1.73 \mathrm{~m}^{2}$, i.e. at the borderline of CKD stages 3-4.
\end{abstract}




\section{Kidney Blood Pressure Research}

Eiselt/Rajdl/Racek/Vostrý/Rulcová/Wirth: ADMA and Progression of CKD

\section{Introduction}

Inhibition of nitric oxide synthesis both in vivo and in vitro by asymmetric dimethylarginine (ADMA) was described more than 20 years ago [1]. Asymmetric dimethylarginine is currently accepted as an active mediator of endothelial dysfunction and an independent predictor of cardiovascular (CV) risk and mortality in both the general population and maintenance dialysis patients $[2,3]$. For persons in the earlier stages of CKD, the situation is not so clear. Chronic kidney disease stage 3-4 patients with higher ADMA had a worse long-term prognosis of CV outcome [4]. Other studies have failed to confirm these findings. In a study of 221 non-dialysis patients with CKD, the levels of ADMA were only slightly higher compared with those of controls and did not correlate with GFR, coronary heart disease, and left ventricular hypertrophy [5]. In addition to its effect on the endothelium, ADMA may have a direct toxic effect on renal tissue. In an animal experiment, increased concentrations of ADMA caused renal fibrosis [6]. Renal tubular cells play an important part in the metabolism of ADMA [7]. Oxidative stress and reduction of tubular mass in CKD may dysregulate or reduce the capacity of enzymatic elimination of ADMA [8]. Other factors, such as hyperhomocysteinemia or inflammation, may also impair ADMA degradation, while therapy with some drugs (e.g. ACE inhibitors) can have a positive effect [2].

Previous studies have usually analyzed single datasets of ADMA without taking into consideration the development of ADMA and related variables over time in the individual patient. However, the rates of glomerular and tubular dysfunction progression are variable. Progression of CKD and parallel changes in other biochemical variables including ADMA may affect each other. The aim of our study was to investigate, in a larger group of nondialysis persons with CKD stages 3-5, changes in the serum levels of ADMA in the course of one year. At the beginning of the study, and at months 6 and 12, changes of oxidative stress, other factors affecting ADMA metabolism, and glomerular and tubular function were also monitored. In addition, associations of ADMA with co-morbidities and pharmacotherapy were studied.

\section{Material and Methods}

\section{Study populations}

The study included 181 patients from the nephrology outpatient clinic of a university hospital. A control group consisted of 46 age-, sex-, smoking-, and body mass index-matched volunteers without a history of kidney disease, and with normal urinalysis and urine sediment. All participants were in stable condition for at least 3 months before the initiation of the study, and their comorbidities related to endothelial dysfunction (hypertension, ischemic heart disease, peripheral arterial disease, diabetes mellitus) were effectively treated. Hypertension was defined as blood pressure $>140 / 90 \mathrm{mmHg}$ and/or antihypertensive medication. Basic characteristics of all participants are shown in Table 1. Exclusion criteria included malignancy, thyreopathy, liver disease, infectious disease, and immunosuppressive therapy. Causes of kidney disease were diabetic nephropathy (DN) in 35 (19\%), glomerulonephritis (GN) in 39 (21\%), adult polycystic kidney disease (APKD) in 9 (5\%), tubulointerstitial nephritis (TIN) in $46(25 \%)$, and hypertensive nephrosclerosis or ischemic nephropathy (HN/IN) in 52 (29\%) patients. A total of 8 elderly controls with a negative history of kidney disease, normal ultrasound, urinalysis, and urinary sediment had estimated GFR (eGFR) $<60 \mathrm{~mL} / \mathrm{min} / 1.73 \mathrm{~m}^{2}$ according to the 2009 CKD-EPI creatinine equation. Therefore, we used, in accordance with the current recommendations the 2012 CKD-EPI cystatin C equation [9]. With this equation, controls had on average a 15\% higher eGFR, and all met the inclusion criterion of eGFR $>60 \mathrm{~mL} /$ $\mathrm{min} / 1.73 \mathrm{~m}^{2}$. The difference was probably due to a very good nutritional status and muscle mass of the elderly control subjects. To prevent underestimation of GFR and to save comparability of data, we present, in both patients and controls, only eGFR values calculated using 2012 CKD-EPI cystatin C equation. Study visits were performed at baseline and, in CKD patients, also after 6 and 12 months. A total of 17 patients (5 with DN, 6 with HT/IN, 1 with PKD, and 4 with TIN) did not complete the follow-up due to death ( $n=2$ ), initiation of dialysis $(n=2)$ or did not their blood samples drawn at months 6 and 12. The Ethics Committee 


\section{Kidney \\ Blood Pressure Research}

Table 1. Basic characteristics and biochemical variables in the serum and urine of patients and controls.

\begin{tabular}{|c|c|c|c|}
\hline & Patients $(n=181)$ & Controls $(n=46)$ & $\mathrm{P}$ \\
\hline Age, years & $66(57-74)$ & $63(52-71)$ & 0.10 \\
\hline Male, $\mathrm{n}(\%)$ & $101(56)$ & $21(46)$ & 0.29 \\
\hline Body mass index, $\mathrm{kg} / \mathrm{m}^{2}$ & $27.2(24.9-31.9)$ & $26.8(23.4-29.7)$ & 0.07 \\
\hline Smokers, n (\%) & $35(19)$ & $11(24)$ & 0.63 \\
\hline Arterial hypertension, n (\%) & $169(93)$ & $25(54)$ & $<0.001$ \\
\hline Diabetes, n (\%) & $74(41)$ & $1(2)$ & $<0.001$ \\
\hline Ischemic heart or peripheral arterial disease, $\mathrm{n}(\%)$ & $75(41)$ & $2(4)$ & $<0.001$ \\
\hline ACE inhibitors, n (\%) & $129(71)$ & $20(44)$ & $<0.001$ \\
\hline Angiotensin II receptor blockers, n (\%) & $65(36)$ & $8(17)$ & 0.03 \\
\hline Beta-blockers, n (\%) & $97(54)$ & $8(17)$ & $<0.001$ \\
\hline Calcium channel blockers, n (\%) & $98(54)$ & $7(15)$ & $<0.001$ \\
\hline Statins, n (\%) & $91(50)$ & $9(20)$ & $<0.001$ \\
\hline Asymmetric dimethylarginine, $\mu \mathrm{mol} / \mathrm{L}$ & $0.87(0.79-0.98)$ & $0.77(0.69-0.86)$ & $<0.001$ \\
\hline Advanced glycation end products, $\mathrm{FU} / \mathrm{g}$ of protein & $1.62(1.38-1.93)$ & $1.42(1.30-1.58)$ & $<0.001$ \\
\hline Advanced oxidation protein products, $\mu \mathrm{mol} / \mathrm{L}$ & $143(123-163)$ & $110(102-123)$ & $<0.001$ \\
\hline Homocysteine, $\mu \mathrm{mol} / \mathrm{L}$ & $21.9(17.5-30)$ & $13.7(10.7-16.1)$ & $<0.001$ \\
\hline $\mathrm{eGFR}, \mathrm{mL} / \mathrm{min} / 1.73 \mathrm{~m}^{2}$ & $22.1(17-35.7)$ & $90(77-104)$ & $<0.001$ \\
\hline Protein/creatinine ratio in urine, $\mathrm{mg} / \mathrm{mmol}$ & $46(11-154)$ & $3(2-5)$ & $<0.001$ \\
\hline Cystatin $\mathrm{C} /$ creatinine ratio in urine, $\mathrm{mg} / \mathrm{mol}$ & $26(10-151)$ & $10(8-16)$ & $<0.001$ \\
\hline GGT/creatinine ratio in urine, $\mu \mathrm{kat} / \mathrm{mol}$ & $50(28-66)$ & $65(50-89)$ & $<0.001$ \\
\hline Albumin, g/L & $45(41.9-48)$ & $48.7(47.2-50.5)$ & $<0.001$ \\
\hline Cholesterol, mmol/L & $4.8(4.1-5.5)$ & $5.4(4.8-5.7)$ & $<0.001$ \\
\hline Triglycerides, mmol/L & $1.6(1.2-2.2)$ & $1.3(0.9-1.8)$ & 0.013 \\
\hline C-reactive protein, mg/L & $3(1-8)$ & $1(1-2)$ & $<0.001$ \\
\hline Hemoglobin in blood, g/L & $126 \pm 19$ & $145 \pm 14$ & $<0.001$ \\
\hline \multicolumn{4}{|c|}{$\begin{array}{l}\text { Data are expressed as median (IQR), mean } \pm \text { SD or a number of patients (n) and a percentage; } \\
\text { biochemical values are in serum, if not stated otherwise; Mann-Whitney and } \chi^{2} \text { tests were used as } \\
\text { appropriate; ACE: angiotensin-converting enzyme, eGFR: estimated glomerular filtration rate using the } \\
2012 \text { CKD-EPI cystatin C equation, GGT: gamma-glutamyl transpeptidase }\end{array}$} \\
\hline
\end{tabular}

of the University Hospital of Plzen approved the study and all participants gave their written consent to participate.

\section{Biochemical measurements}

Blood samples were collected in the morning hours after a $10 \mathrm{~h}$ fast from a peripheral vein during study visits. Asymmetric dimethylarginine, advanced glycation end products (AGE), advanced oxidation protein products (AOPP), homocysteine (HCY), creatinine, cystatin C, albumin, total cholesterol, triglycerides, and C-reactive protein levels were measured in serum, and hemoglobin in blood. Variables determined in morning urine samples included cystatin C, gamma-glutamyl transpeptidase (GGT), protein, and creatinine.

Blood and urine samples were transported to a laboratory within 30 minutes and processed immediately thereafter. Blood samples were centrifuged for 8 minutes at $2200 \mathrm{~g}$ and samples were stored at $-80{ }^{\circ} \mathrm{C}$ until analysis. Sample analysis was performed batch-wise. Asymmetric dimethylarginine levels were assessed by ELISA (ADMA ${ }^{\circledR}$ ELISA kit, DLD Diagnostika GmbH, Germany) performed on an AUTOEIA II microplate reader (Labsystems Oy, Finland). Advanced glyaction end products were determined by a fluorescence method described elsewhere [10], with modification on microplates, excitation $365 \mathrm{~nm}$, emission 440 nm; Cary Elipse Fluorescence Spectrophotometer (Varian Crompack Int. BV, the Netherlands) and expressed as fluorescence units/g of plasma protein (FU/g). Plasma AOPPs were measured using a photometric method (detection at $340 \mathrm{~nm}$, AUTO-EIA II microplate reader) [11]. Cystatin C in plasma and urine were determined by particle-enhanced immunoturbidimetry (Dako A/S, Glostrup, Denmark). Gamma-glutamyl transpeptidase in urine was measured using an enzymatic photometric assay (Beckman Coulter, Brea, CA, USA). All other laboratory variables were measured using standard analytical techniques. Protein, cystatin $\mathrm{C}$, and GGT in urine were expressed as a ratio of the concentration of the substance to the concentration of creatinine [U_prot/U_cr (mg/mmol), U_cysC/U_cr (mg/mol), and U_GGT/U_cr $(\mu \mathrm{kat} / \mathrm{mol})]$, respectively. 


\section{Kidney \\ Blood Pressure Research}

Eiselt/Rajdl/Racek/Vostrý/Rulcová/Wirth: ADMA and Progression of CKD

Table 2. Asymmetric dimethylarginine, oxidative stress, renal functions and other parameters during one-year follow-up

\begin{tabular}{|c|c|c|c|c|}
\hline & \multicolumn{3}{|c|}{ Patients with CKD stages 3-5 (n=164) } & \multirow[b]{2}{*}{$P$} \\
\hline & Month 0 & Month 6 & Month 12 & \\
\hline Asymmetric dimethylarginine, $\mu \mathrm{mol} / \mathrm{L}$ & $0.87(0.79-0.96)$ & $0.89(0.76-1.01)$ & $0.89(0.76-1.01)$ & 0.80 \\
\hline Advanced glycation end products, FU/g of protein & $1.58(1.38-1.90)$ & $1.74(1.51-2.18)^{\mathrm{a}}$ & $1.76(1.52-2.21)^{\mathrm{a}}$ & $<0.001$ \\
\hline Advanced oxidation protein products, $\mu \mathrm{mol} / \mathrm{L}$ & $142(123-164)$ & $137(119-153)$ & $142(122-171)$ & 0.06 \\
\hline Homocysteine, $\mu \mathrm{mol} / \mathrm{L}$ & $21,6(17.3-29.9)$ & $22.3(17.8-28.1)$ & $23.4(19-30.8)$ & 0.20 \\
\hline $\mathrm{eGFR}, \mathrm{mL} / \mathrm{min} / 1.73 \mathrm{~m}^{2}$ & $23.5(17.7-36)$ & $23(16.6-35.1)$ & $21(14.7-31.5)^{\mathrm{a}}$ & 0.018 \\
\hline Protein/creatinine ratio in urine, $\mathrm{mg} / \mathrm{mmol}$ & $42(10-151)$ & $47(9-182)$ & $36(11-169)$ & 0.92 \\
\hline Cystatin $\mathrm{C} /$ creatinine ratio in urine, $\mathrm{mg} / \mathrm{mol}$ & $22(10-108)$ & $23(12-151)$ & $19(9-102)$ & 0.14 \\
\hline GGT $/$ creatinine ratio in urine, $\mu \mathrm{kat} / \mathrm{mol}$ & $50(27-66)$ & $46(28-80)$ & $48(24-74)$ & 0.88 \\
\hline Albumin, $\mathrm{g} / \mathrm{L}$ & $44.6 \pm 4.4$ & $45.9 \pm 4.3$ & $45.3 \pm 4$ & 0.30 \\
\hline Cholesterol, mmol/L & $4.8(4.1-5.5)$ & $4.6(4-5.5)$ & $4.6(3.9-5.3)$ & 0.13 \\
\hline Triglycerides, $\mathrm{mmol} / \mathrm{L}$ & $1.6(1.2-2.2)$ & $1.5(1.1-2)$ & $1.5(1-2)$ & 0.18 \\
\hline C-reactive protein, $\mathrm{mg} / \mathrm{L}$ & $3(1-6)$ & $2(1-7)$ & $3(1-6)$ & 0.38 \\
\hline Hemoglobin in blood, $\mathrm{g} / \mathrm{L}$ & $127 \pm 18$ & $128 \pm 18$ & $124 \pm 18$ & 0.14 \\
\hline $\begin{array}{l}\text { Values are in serum, if not stated otherwise, and } \\
\text { glomerular filtration rate using the } 2012 \text { CKD-EP } \\
\text { Kruskal-Wallis One Way Analysis of Variance on } \\
\text { Multiple Comparison Procedures (Tukey Test or }\end{array}$ & m-Sidak meth & (IQR) or mea & $\begin{array}{l}\text { wed by All Pai } \\
\text { th } 0\end{array}$ & \\
\hline
\end{tabular}

Statistics

Continuous data are expressed as median (IQR) or mean \pm SD. For paired and non-paired comparisons, the Mann-Whitney test and t-test were used as appropriate. Differences among variables at baseline, and after 6 and 12 months were tested with Kruskal-Wallis one-way analysis of variance on ranks or one-way analysis of variance followed by all pairwise multiple comparison procedures (Tukey test or Holm-Sidak method). Categorical variables are expressed as percentages and were analyzed by the chi-square test. To identify factors of progression, a stepwise backward and forward algorithm for a linear regression model was used with the change of eGFR per year as a dependent variable and the following independent variables: age, sex, BMI, smoking, cause of CKD, eGFR, serum ADMA, AOPPs, AGEs, homocysteine; interaction of ADMA, AOPPs, AGEs and homocysteine with eGFR; U_GGT/U_cr, U_cysC/U_cr, U_prot/U_cr, change of U_prot/U_cr per year, cholesterol, triglycerides, C-reactive protein, blood hemoglobin, diabetes mellitus, hypertension, coronary, and peripheral arterial disease, and use of statins, ACE inhibitors or ARBs. All P values were twotailed and values of $\mathrm{P}<0.05$ were considered statistically significant. Analyses were carried out using R 3.0.1. software [R Foundation for Statistical Computing, 2013, Vienna, Austria; http://www.r-project.org].

\section{Results}

Basic characteristics and biochemical variables of patients and controls are given in Table 1. In comparison with controls, patients had significantly elevated ADMA, markers of oxidative stress, and homocysteine. The urinary excretion of cystatin $\mathrm{C}$ was increased in CKD, while excretion of GGT was lower than in controls.

Changes in monitored variables at baseline and after 6 and 12 months are summarized in Table 2. The levels of ADMA were stable throughout the one-year follow-up. Value of eGFR decreased at the end of the study by $12 \%$ and AGE rose significantly. The rates of urinary excretion of protein, GGT, and cystatin $C$ were unchanged.

According to multiple linear regression, the rate of progression of eGFR was determined by the interaction between higher baseline eGFR and higher ADMA, and between higher baseline eGFR and higher AOPP. Patients with these characteristics had the most severe progression of CKD after a year of follow-up, as explained in detail in Figure 1. The regression model revealed that not only the above interactions but, also, higher baseline AGE levels, proteinuria, hypertension, and baseline eGFR were factors of progression (Table 3). 


\section{Kidney Blood Pressure Research}

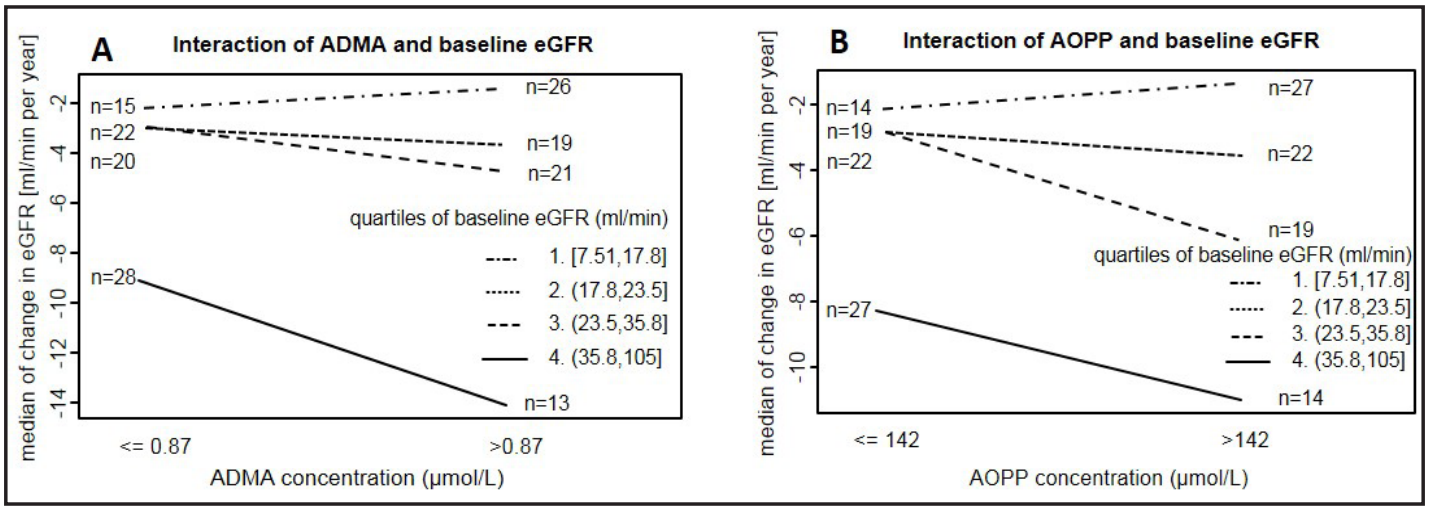

Fig. 1. Interaction of baseline eGFR with ADMA (A) and AOPP (B) in relation to eGFR change per year ( $\mathrm{n}=164$, patients with complete, one-year follow-up). Numbers on the left and right side of eGFR quartiles denote counts of patients belonging to the quartile above and below median of appropriate variable (ADMA or AOPP). A. Graphic representation of interactions reveals that patients with baseline eGFR in the highest quartile (> $\left.36 \mathrm{~mL} / \mathrm{min} / 1.73 \mathrm{~m}^{2}\right)$ with ADMA levels higher than median $(0.87 \mu \mathrm{mol} / \mathrm{l})$ had the most severe decline of eGFR. B. In the case of AOPP, interaction of baseline eGFR higher than median (>24 mL/ min $\left./ 1.73 \mathrm{~m}^{2}\right)$ with AOPP levels higher than median $(142 \mu \mathrm{mol} / \mathrm{L})$ predicted the highest decrease in eGFR.

\section{Discussion}

ADMA in patients and controls

We documented increased ADMA in 181 patients with CKD stages 3-5 compared with 46 age-, sex-, smoking habits- and body mass indexmatched controls without kidney disease. The difference in ADMA was only $13 \%$ and was stable after 6 and 12 months. The small differences contrast with the results of Kielstein reporting that, in patients with IgA nephropathy or polycystic kidney disease with GFR of $120 \mathrm{~mL} / \mathrm{min}$, ADMA levels were three times higher compared with controls [12]. Kielstein's controls were young non-smokers without a
Table 3. Factors of CKD progression

\begin{tabular}{|c|c|c|c|}
\hline & Estimate & Std. Error & $\mathrm{P}$ \\
\hline (Intercept) & 33.14 & 9.1984 & 0.0004 \\
\hline eGFR (CKD-EPI cysC) [ml/min] & -0.4988 & 0.2230 & 0.0267 \\
\hline U_GGT/U_cr $[\mu \mathrm{kat} / \mathrm{mol}]$ & 0.0254 & 0.0138 & 0.0687 \\
\hline U_prot/U_cr $[\mathrm{mg} / \mathrm{mmol}]$ & -0.0085 & 0.0027 & 0.0026 \\
\hline ADMA $[\mu \mathrm{mol} / \mathrm{L}]$ & 3.2194 & 6.1333 & 0.6004 \\
\hline $\mathrm{AOPP}[\mu \mathrm{mol} / \mathrm{L}]$ & -0.0706 & 0.0387 & 0.0700 \\
\hline AGE [FU/g of protein] & -5.4935 & 1.6138 & 0.0008 \\
\hline Cholesterol [mmol/l] & 1.0241 & 0.5283 & 0.0544 \\
\hline Triglycerides [mmol/l] & -1.0951 & 0.5851 & 0.0632 \\
\hline BMI $\left[\mathrm{kg} / \mathrm{m}^{2}\right]$ & -0.1536 & 0.1069 & 0.1529 \\
\hline Hypertension $[0 / 1]$ & -6.5222 & 2.5001 & 0.0100 \\
\hline Interaction eGFR : ADMA & -0.4074 & 0.1695 & 0.0174 \\
\hline Interaction eGFR : AOPP & 0.00271 & 0.0013 & 0.0406 \\
\hline
\end{tabular}

Adjusted R2: 0.49, $\mathrm{p}<0.0001$;

Stepwise backward and forward linear regression using change in eGFR per year as dependent variable; independent variables included: ADMA, AOPPs, AGEs, homocysteine; interaction of ADMA, AOPPs, AGEs, and homocysteine with eGFR; age, sex, cause of CKD, eGFR, U_GGT/U_cr, U_cysC/U_cr, U_prot/U_cr, change in U_prot/U_cr per year, cholesterol, triglycerides, C-reactive protein, hemoglobin, BMI, smoking, diabetes, hypertension, cardiovascular disease, use of statins, ACE inhibitors, ARBs

CV disease, while our controls were 20 years older, $24 \%$ of them were smokers, and $50 \%$ had hypertension. Our control group is therefore more compatible with the population of patients with CKD stages 3-5. The difference may also be partly due to the different method of measurement of ADMA (HPLC versus ELISA) and the small set of patients and controls compared in our study. Asymmetric dimethylarginine levels of our controls (median 0.77 $\mu \mathrm{mol} / \mathrm{L})$ were comparable with values found in the highest quintile $(0.71 \mu \mathrm{mol} / \mathrm{L})$ of one population study [13]. These persons had the highest risk of a CV event. However, it was a population of younger premenopausal woman without comorbidities, while our controls had substantially more CV risk factors. Similarly, small differences between patients and controls were found by Fleck et al. [5]. Healthy controls in Fleck's study had ADMA levels 


\section{Kidney Blood Pressure Research}

of $0.66 \mu \mathrm{mol} / \mathrm{L}$ and the levels of non-dialysis patients with chronic renal failure (GFR not shown) were $0.91 \mu \mathrm{mol} / \mathrm{L}$.

Progression of CKD and baseline eGFR, ADMA and oxidative stress

The most interesting result of our study was the observation that the rate of progression ofCKD depends on the interaction of elevations of ADMA, AOPP, and baseline eGFR. High levels of ADMA and AOPP were predictors of rapid progression only with higher baseline eGFR values. Asymmetric dimethylarginine and AOPP were identified as factors of progression at initial eGFR $>36 \mathrm{~mL} / \mathrm{min} / 1.73 \mathrm{~m}^{2}$ and $>24 \mathrm{~mL} / \mathrm{min} / 1.73 \mathrm{~m}^{2}$, respectively. We can speculate that therapeutic interventions against accumulation of ADMA and AOPP would be effective only in patients with higher filtration rates than these approximate "cut-off" values of eGFR.

Our results are partially consistent with the findings of Fliser who reported a correlation of GFR with ADMA in 227 non-diabetic persons with mild-to-moderate kidney disease [14]. Progressors to ESRD or to doubling of serum creatinine had higher ADMA and mean GFR of $38 \mathrm{ml} / \mathrm{min} / 1.73 \mathrm{~m}^{2}$.

Oxidative stress, glomerular and tubular function

Patients had significantly higher variables of oxidative stress and homocysteine compared with controls. Advanced glycation end products also rose significantly during the one-year observation period. Oxidative stress and homocysteine are known to inhibit ADMA metabolism $[2,15]$. A substantial proportion of hydrolytic degradation of ADMA catalyzed by dimethylarginine dimethylaminohydrolase (DDAH) occurs in tubular cells, while direct excretion to urine is of little importance [16]. According to one hypothesis, tubular cell dysfunction causes, particularly in diabetic nephropathy, dysregulation of the uptake and metabolism of ADMA and homocysteine [8]. In our patients, the decline of eGFR was $12 \%$ per year (median $2.5 \mathrm{~mL} / \mathrm{min} / 1.73 \mathrm{~m}^{2}$ ). The capacity of reduced tubular mass to metabolize filtered cystatin $\mathrm{C}$ was lower than in controls, but stable throughout the year. Enzymuria measured as GGT excretion rate was lower in patients than in controls and also did not change. It has long been known that patients with stable CKD without acute tubular damage have lower GGT in urine than healthy persons. This is a consequence of chronically reduced tubular cells mass without concurrent tubulotoxic insults $[17,18]$. Stabilized ADMA and tubular functions support our hypothesis that the gradual scaring of residual nephrons leads to a decrease in GFR, but the metabolic capacity of tubular cells can maintain balanced levels of ADMA. This may be true in the absence of acute tubulotoxic factors, e.g. iatrogenic or infectious.

Inflammation, hyperlipidemia and comorbidities associated with endothelial dysfunction

Inflammation may increase ADMA concentrations [16]. For people with moderateto-severe CKD, chronic inflammation is an important potential cause of anemia and malnutrition. Our patients had stable and low C-reactive protein, normal albumin, and were without substantial anemia. Patients with hypercholesterolemia exhibit elevated ADMA and impaired endothelium-dependent vasodilation [19]. Our patients, as a group at high CV risk, were intensively treated with statins. Statins were prescribed to $50 \%$ of our CKD patients and $20 \%$ of our controls. That was probably why the patients had significantly lower cholesterol than the control group. The medians of albumin (45-46 g/L) and C-reactive protein (2-3 $\mathrm{mg} / \mathrm{L}$ ) throughout the year exclude malnutrition or chronic infection as a cause of low cholesterol. Some authors reported that statins, due to their pleiotropic effects, can reduce ADMA [20]. In one study, simvastatin with oral L-arginine improved endothelial dysfunction of subjects with high ADMA [21]. However, the results are inconsistent. The design of our study does not allow for assessing a possible causal effect of statins on ADMA levels.

Cardiovascular diseases and diabetes are associated with endothelial dysfunction and increased ADMA both in the general population and in CKD $[2,22]$. To distinguish the effect of CKD on ADMA from that of other CV risk factors, we sought to enroll control subjects matched in age, gender, smoking habits, body mass index, and CV comorbidities. However, as is evident from Table 1, it was impossible to find enough CKD-free volunteers with an 


\section{Kidney \\ Blood Pressure Research}

Kidney Blood Press Res 2014;39:50-57

\begin{tabular}{l|l}
\hline DOI: $10.1159 / 000355776$ & (C) 2014 S. Karger AG, Basel
\end{tabular}

Publisned onIIne: June 03, 2014

www.karger.com/kbr

Eiselt/Rajdl/Racek/Vostrý/Rulcová/Wirth: ADMA and Progression of CKD

incidence of comorbidities comparable to that of the CKD population. Therefore, as one might expect, all patients were treated with either ACE inhibitors or angiotensin 2 receptor blockers (ARBs), and some patients had a combination of both. According to some experimental and clinical studies, ACE inhibitors and ARBs may improve endothelial dysfunction and lower ADMA levels [23-25]. While the clinical relevance of this effect is unknown, an effect of administration of an ACE inhibitor/ARB on the small differences in serum ADMA between our patients and controls seems possible.

\section{Limitations}

Some limitations of our study should be mentioned. First, the observational nature of the study does not prove causality of the associations found. Second, in comparison with direct measurement of GFR, the estimate of GFR based on serum cystatin C levels can be biased. However, in a group of relatively stable CKD patients, changes of GFR (the primary outcome in our study) are not likely to be influenced by this potential bias.

\section{Conclusions}

We present a prospective controlled one-year follow-up study of the effects of ADMA, oxidative stress, and other variables related to ADMA metabolism on the progression of kidney dysfunction in 181 patients with CKD stages 3-5. We also enrolled a control group consisting of 46 age-, sex-, smoking habits- and body mass index-matched individuals without kidney disease.

In CKD patients, the risk factors of progression were the interactions of high baseline levels of ADMA with baseline eGFR $>36 \mathrm{ml} / \mathrm{min} / 1.73 \mathrm{~m}^{2}$ and high baseline AOPP with baseline eGFR $>24 \mathrm{ml} / \mathrm{min} / 1.73 \mathrm{~m}^{2}$, respectively. A faster decline of eGFR was also associated with increased AGE, hypertension and proteinuria. Patients with these characteristics seem to be the population at risk in terms of rapid progression of CKD. They could be potential candidates of future therapies, e.g. those aimed at the DDAH/ADMA pathway or antioxidant defense.

\section{Disclosure Statement}

The authors declare that they have no conflict of interest.

\section{Acknowledgements}

The study was supported by the project CZ.1.05/2.1.00/03.0076 from European Regional Development Fund and by the Charles University Research Project [P36].

\section{References}

1 Vallance P, Leone A, Calver A, Collier J, Moncada S: Accumulation of an Endogenous Inhibitor of Nitric Oxide Synthesis in Chronic Renal Failure. Lancet 1992;339:572-575.

-2 Sibal L, Agarwal SC, Home PD, Boger RH: The Role of Asymmetric Dimethylarginine (ADMA) in Endothelial Dysfunction and Cardiovascular Disease. Curr Cardiol Rev 2010;6:82-90.

-3 Zoccali C, Bode-Böger SM, Mallamaci F, Benedetto FA, Tripepi G, Malatino LS, Cataliotti A, Bellanuova I, Fermo I, Frölich JC, Böger RH: Plasma concentration of asymmetrical dimethylarginine and mortality in patients with end-stage renal disease: a prospective study. The Lancet 2001;358:2113-2117.

-4 Lu T-M, Chung M-Y, Lin C-C, Hsu C-P, Lin S-J: Asymmetric Dimethylarginine and Clinical Outcomes in Chronic Kidney Disease. Clin J Am Soc Nephrol 2011;6:1566-1572.

$>5$ Fleck C, Schweitzer F, Karge E, Busch M, Stein G: Serum concentrations of asymmetric (ADMA) and symmetric (SDMA) dimethylarginine in patients with chronic kidney diseases. Clin Chim Acta 2003;336:112. 


\section{Kidney \\ Blood Pressure Research}

Kidney Blood Press Res 2014;39:50-57

\begin{tabular}{l|l}
\hline DOI: $10.1159 / 000355776$ & (C) 2014 S. Karger AG, Basel
\end{tabular}

www.karger.com/kbr

6 Mihout F, Shweke N, Bigé N, Jouanneau C, Dussaule J-C, Ronco P, Chatziantoniou C, Boffa J-J: Asymmetric dimethylarginine (ADMA) induces chronic kidney disease through a mechanism involving collagen and TGF- $\beta 1$ synthesis. J Pathol 2011;223:37-45.

7 Tojo A, Welch WJ, Bremer V, Kimoto M, Kimura K, Omata M, Ogawa T, Vallance P, Wilcox CS: Colocalization of demethylating enzymes and NOS and functional effects of methylarginines in rat kidney. Kidney Int 1997;52:1593-1601.

-8 Saito A, Kaseda R, Hosojima M, Sato H: Proximal Tubule Cell Hypothesis for Cardiorenal Syndrome in Diabetes. Int J Nephrol 2010;2011:1-9.

9 Kidney Disease: Improving Global Outcomes (KDIGO) CKD Work Group: KDIGO 2012 Clinical Practice Guideline for the Evaluation and Management of Chronic Kidney Disease. Kidney Int Suppl 2013:1-150.

-10 Münch G, Keis R, Wessels A, Riederer P, Bahner U, Heidland A, Niwa T, Lemke HD, Schinzel R: Determination of advanced glycation end products in serum by fluorescence spectroscopy and competitive ELISA. Eur J Clin Chem Clin Biochem 1997;35:669-677.

11 Witko-Sarsat V, Friedlander M, Capeillere-Blandin C, Nguyen-Khoa T, Nguyen AT, Zingraff J, Jungers P, Descamps-Latscha B: Advanced oxidation protein products as a novel marker of oxidative stress in uremia. Kidney Int 1996;49:1304-1313.

12 Kielstein JT, Böger RH, Bode-Böger SM, Frölich JC, Haller H, Ritz E, Fliser D: Marked Increase of Asymmetric Dimethylarginine in Patients with Incipient Primary Chronic Renal Disease. J Am Soc Nephrol 2002;13:170-176.

13 Leong T, Zylberstein D, Graham I, Lissner L, Ward D, Fogarty J, Bengtsson C, Björkelund C, Thelle D: Asymmetric Dimethylarginine Independently Predicts Fatal and Nonfatal Myocardial Infarction and Stroke in Women 24-Year Follow-Up of the Population Study of Women in Gothenburg. Arterioscler Thromb Vasc Biol 2008;28:961-967.

14 Fliser D, Kronenberg F, Kielstein JT, Morath C, Bode-Böger SM, Haller H, Ritz E: Asymmetric Dimethylarginine and Progression of Chronic Kidney Disease: The Mild to Moderate Kidney Disease Study. J Am Soc Nephrol 2005;16:2456-2461.

15 Yilmaz MI, Saglam M, Caglar K, Cakir E, Sonmez A, Ozgurtas T, Aydin A, Eyileten T, Ozcan O, Acikel C, Tasar M, Genctoy G, Erbil K, Vural A, Zoccali C: The Determinants of Endothelial Dysfunction in CKD: Oxidative Stress and Asymmetric Dimethylarginine. Am J Kidney Dis 2006;47:42-50.

16 Teerlink T: ADMA metabolism and clearance. Vasc Med 2005;10:S73-81.

17 Maruhn D, Fuchs I, Mues G, Bock KD: Normal limits of urinary excretion of eleven enzymes. Clin Chem 1976;22:1567-1574.

18 Kley R, Bahre G, Holzhüter H: [Determination of gamma-glutamyl transpeptidase in the urine of normal persons and patients with kidney disease, using an automatic kinetic method (author's transl)]. Z Für Klin Chem Klin Biochem 1973;11:537-542.

19 Böger RH, Bode-Böger SM, Szuba A, Tsao PS, Chan JR, Tangphao O, Blaschke TF, Cooke JP: Asymmetric Dimethylarginine (ADMA): A Novel Risk Factor for Endothelial Dysfunction Its Role in Hypercholesterolemia. Circulation 1998;98:1842-1847.

20 Lu T-M, Ding Y-A, Lin S-J, Lee W-S, Tai H-C: Plasma levels of asymmetrical dimethylarginine and adverse cardiovascular events after percutaneous coronary intervention. Eur Heart J 2003;24:1912-1919.

-21 Böger GI, Rudolph TK, Maas R, Schwedhelm E, Dumbadze E, Bierend A, Benndorf RA, Böger RH: Asymmetric Dimethylarginine Determines the Improvement of Endothelium-Dependent Vasodilation by Simvastatin: Effect of Combination With Oral L-Arginine. J Am Coll Cardiol 2007;49:2274-2282.

-22 Krzyzanowska K, Mittermayer F, Wolzt M, Schernthaner G: Asymmetric Dimethylarginine Predicts Cardiovascular Events in Patients With Type 2 Diabetes. Diabetes Care 2007;30:1834-1834.

23 Li D, Xia K, Li N-S, Luo D, Wang S, Jiang D-J, Deng H-W, Li Y-J: Reduction of asymmetric dimethylarginine involved in the cardioprotective effect of losartan in spontaneously hypertensive rats. Can J Physiol Pharmacol 2007;85:783-789.

24 Delles C, Schneider MP, John S, Gekle M, Schmieder RE: Angiotensin Converting Enzyme Inhibition and Angiotensin II AT1-Receptor Blockade Reduce the Levels of Asymmetrical NG, NG-Dimethylarginine in Human Essential Hypertension*. Am J Hypertens 2002;15:590-593.

25 Ito A, Egashira K, Narishige T, Muramatsu K, Takeshita A: Angiotensin-Converting Enzyme Activity is Involved in the Mechanism of Increased Endogenous Nitric Oxide Synthase Inhibitor in Patients With Type 2 Diabetes Mellitus. Circ J 2002;66:811-815. 